\title{
Mobilization Under Threat: Emotional Appeals and Pro-Opposition Political Participation Online
}

\author{
Lauren E. Young ${ }^{1}$ (D)
}

Accepted: 17 April 2021

(c) The Author(s) 2021

\begin{abstract}
Large numbers of people living under authoritarian governments participate in proopposition politics despite sometimes significant risks. Increasing amounts of this political participation are taking place and being organized online. Do emotions play a causal role in inducing pro-opposition participation in authoritarian regimes? Can emotions that mobilize participation be spread via social media? Through an experiment carried out by an opposition party in Zimbabwe, I test whether campaign appeals to opposition supporters' emotions affect their level of political participation in online pro-opposition discussions. I find that across two different issue areas, randomly assigned anger appeals increase participation on average by 0.4 standard deviations more than enthusiasm appeals with the same informational content. In real terms, this represents between $30 \%$ and $170 \%$ more participation in the groups assigned to the anger appeals across four different measures of participation. There is little evidence that these effects are stronger in areas with less poverty or that have historically been affected by more violence, or when coupled with messages emphasizing personal power. These results suggest that anger appeals that highlight economic grievances can be an important force for mobilizing online political participation in repressive environments.
\end{abstract}

\footnotetext{
My thanks to the team at Transform Zimbabwe. Thanks to Graeme Blair, Christopher Blattman, Christopher Claessen, Alexander Coppock, Albert Fang, Grant Gordon, Donald Green, Macartan Humphreys, Elizabeth Levy-Paluck, George Marcus, Isabela Mares, Marika Miner, Tamar Mitts, Suresh Naidu, Gabriella Sacramone-Lutz, Anastasia Shesterinina, Susan Stokes, and Thomas Zeitzoff for comments on the design and analysis of this project, as well as seminar audiences at the European Political Science Association, the Households in Conflict Network, and American Political Science Association annual meetings. The author thanks the U.S. Institute for Peace, the International Peace Research Association Foundation, and the National Science Foundation for support for her travel and time. The intervention described in this paper was funded and implemented by Transform Zimbabwe. This study was determined to be "not human subjects research" by the Columbia University Institutional Review Board decision on protocol AAAP0700. The research design and hypotheses were preregistered on the EGAP design database on March 20, 2015, and can be accessed at http://egap.org/registration/741. Replication materials are available via the Harvard Dataverse at https://dataverse.harvard.edu/dataset.xhtml?persistentId=doi:10.7910/ DVN/DSIY7B.
}

Extended author information available on the last page of the article 
Keywords Emotional appeals $\cdot$ Field experiment $\cdot$ Social Media $\cdot$ Political participation

\section{Introduction}

Information and communication technology (ICT), including social media, has become a common channel for citizen mobilization in autocracies around the world. While ICT is clearly not a purely pro-democratic force (King et al., 2017; Roberts, 2018), its potential to spread information and invigorate citizen participation both on- and offline has been demonstrated in cases like Egypt, Iran, China, and Burkina Faso. In Zimbabwe, for example, videos made by a pastor who draped himself in the Zimbabwean flag and recorded irate messages about the state of the economy in the summer of 2016 spread quickly on social media and drove participation in protests. ${ }^{1}$ The fact that internet shutdowns and arrests of social media activists have become a common element in the autocrat's toolkit suggests that authoritarian regimes are also well aware of ICT's potential to mobilize opposition movements that threaten their hold on power (Freedom House, 2019).

Despite widespread recognition that ICT has become a battlefield for pro- and antidemocratic forces, we know little about how pro-opposition participation online actually occurs. Do the strategies of political entrepreneurs make a difference in whether or not people participate in pro-opposition politics online, for instance by joining the Facebook group of an opposition party, sharing its campaign materials via WhatsApp, or expressing support for the opposition on Twitter? If so, what strategies are most effective in mobilizing online pro-opposition participation in non-democratic states? Furthermore, while ICT has typically been conceptualized as a means of spreading information, it clearly also transmits intense emotional content. Does that emotional content have an important effect on subsequent mobilization, or should it be seen as an irrelevant part of the packaging of information about others' preferences and actions?

This article sheds light on these questions through an online field experiment conducted in partnership with an opposition political party called Transform Zimbabwe (TZ) in the spring of 2015. Zimbabwe is an electoral autocracy where the ruling party holds regular elections but uses a range of tactics including state repression to ensure that the opposition has little chance of taking power. In the experiment TZ tested two versions of an emotional appeal that targeted the emotions of anger or enthusiasm by using different images, music, and slight changes in wording while carrying the same informational content. The anger versions of the appeal highlighted economic grievances, while the enthusiasm versions only described the party's positive vision for the future without any negative emotional content. These appeals were randomly assigned to geographically-based WhatsApp groups of TZ's supporters that were then tracked for the following 24 hours. This research design

\footnotetext{
1 Allison, Simon. 26 May 2016. "The man behind \#ThisFlag, Zimbabwe's accidental movement for change". The Guardian. https://www.theguardian.com/world/2016/may/26/this-flag-zimbabwe-evanmawarire-accidental-movement-for-change.
} 
thus tests whether the emotional valence of an opposition party's messages affects online mobilization.

The results show that the anger appeal led to significantly more pro-opposition participation online. Specifically, participation was 0.38 standard deviations higher in groups that received the anger appeal compared to those that received the enthusiasm appeal on an index of four different measures of pro-opposition participation constructed from the WhatsApp group transcripts in the $24 \mathrm{~h}$ after the appeals were sent out. This translates into an average of 1.8 additional messages sent out, 0.6 additional participants, 0.3 additional repetitions of the party slogan, and one additional party symbol being sent out in the groups that received the anger appeal compared to the groups that received the enthusiasm appeal. The effects of the anger appeal were largely consistent across different types of constituencies. These findings suggest that anger can be an important driver of online political mobilization in authoritarian contexts for many different types of citizens.

This study is part of a growing literature on the role of ICT in contentious politics. It is clear that ICT has become a key tool for activists trying to mobilize expressions of dissent in many cases (Breuer et al., 2015; Tufekci \& Wilson, 2012). However, we lack a strong empirical understanding of how ICT may mobilize citizens, and existing studies have tended to theorize ICT as facilitating the spread of information and reducing coordination costs (Enikolopov et al., 2020; Little, 2016; Zeitzoff, 2017). This study shows that even holding information constant, the emotional content transmitted over social media can have a powerful mobilizing effect. This article thus provides additional evidence to the argument by Jost et al. (2018) that social media shapes protest participation by transmitting not only information but also content that affects motivation including messages emphasizing anger, social identification, and collective efficacy. This article joins a growing body of research on the determinants of online political participation in contexts characterized by repression or other forms of coercive violence (Barberá et al., 2015; Pan \& Siegel, 2020).

More broadly, this study contributes to a literature on whether the mobilizing strategies of opposition political parties and activists matter. Previous scholars have argued that the mobilization strategies of political parties can explain transitions to democracy (Bunce \& Wolchik, 2011), opposition party vote share and consolidation (LeBas, 2011), and party identification (Bratton et al., 2012). One key factor in this literature is the extent to which opposition parties employ grievance-based strategies similar to the anger appeals studied here. Group-based grievance appeals have been cited as key mobilizing tactics for parties in emerging multiethnic democracies (Horowitz, 1985), populist right-wing parties in Europe (Ivarsflaten, 2008), and the Republican Party in the U.S. (Valentino et al., 2002). Recent research has used survey experiments to test for the effectiveness of grievance-based electoral appeals in Kenya (Horowitz \& Klaus, 2020). While Horowitz and Klaus (2020) find that explicit grievance appeals increase support among only a small subset of voters, the results of this online field experiment show that the anger-based partisan grievance appeal increased participation across a broad range of demographic groups. The findings here also extend research on the effects of partisan emotional appeals from developed democracies like the U.S. to non-democratic settings (Brader, 2006; Miller \& Krosnick, 2004; Ryan 2012; Weber, 2013). 


\section{Social Media, Emotional Appeals, and Political Mobilization}

Decisions about political participation are made in emotional environments. The perceived stakes of political outcomes-whether a candidate who represents your group is elected, whether policies that will bring real benefits or harms to you will be put into place-are high, and often involve a moral dimension. Political decisions may be even more emotional in non-democratic regimes where the threat of state repression can lead to acute anger and fear among citizens critical of the regime.

A large body of research in psychology and political psychology argues that distinct emotions can have causal effects on subsequent political behavior. Psychologists differ in the emphasis that they place on the cognitive versus non-cognitive channels through which emotions might affect behavior. Some have argued that these pre-cognitive "action tendencies" enable organisms to react to a potentially valuable or dangerous stimulus faster than the logical response to that stimulus can be formulated (LeDoux, 1996; Nico, 1986). Others emphasize the way that emotions arise from and reinforce cognitive appraisals such as perceptions of responsibility, individual control, and certainty (Lerner \& Keltner, 2000).

Because of the effects they can have on behavior, emotions are frequently invoked during political campaigns in both democracies and non-democracies. Political messages appeal to anger about the state of the nation, enthusiasm for a candidate or policy, and fear of national or group-based threats should a certain candidate be elected (Ridout \& Searles, 2011). In less democratic environments, fear appeals may also involve threats directed at individuals or groups (Young, 2019). Brader (2006, pp. 68-69) defines an emotional appeal as "any communication that is intended to elicit an emotional response from some or all who receive it." The literature on emotional appeals in politics also recognizes that emotional appeals can work through both cognitive and non-cognitive channels. First, emotional appeals may trigger automatic responses. Activists, for instance, describe putting people into "attack mode" by transforming "inchoate anxieties and fears... into moral indignation and anger toward concrete policies and decision-makers" (Jasper, 2008, p. 107). Second, emotional appeals may change how cognitive processes function. Emotions in political communications may make their targets more hasty in their decision-making, less skeptical, or more likely to question their preexisting beliefs (Albertson \& Gadarian, 2015). Emotional appeals are transmitted through images, sounds, and ideas that trigger emotional responses (Brader, 2006). Research in established democracies has tended to study emotional appeals in televised advertisements (Brader, 2006). In many non-democratic settings, which tend to be lower-income, emotional appeals are also frequently transmitted through channels like radio, face-to-face rallies, or increasingly, low-cost ICT like Facebook and WhatsApp.

How might appeals with different emotional content affect participation in online pro-opposition groups? Emotions are commonly disaggregated based on their valence and activation. Emotional valence represents the extent to which an emotion is positive or negative, while activation refers to its level of mobilization or energy (Barrett \& Russell, 1999). Other scholars have argued that emotions should also be characterized by a third dimension called "motivational direction" that links 
emotions to either approach or avoidance tendencies (Harmon-Jones et al., 2013). In this three-dimensional space, anger and enthusiasm are both high-activation, approach-oriented emotions that differ in their valence: negative for anger, and positive for enthusiasm. The fact that anger and enthusiasm are both approach-oriented emotions helps explain their common use in emotional appeals designed to compel action.

Yet while both anger and enthusiasm are high in activation and motivational approach, anger may have a particularly powerful mobilizing effect. Enthusiasm is activated when progress towards incentives exceeds expectations, or has the potential to do so, while anger is triggered when progress is blocked (Frijda, 1986). Anger is thus associated with a desire to change the status quo, remove obstacles, or hurt a target (Frijda et al., 1989; Roseman et al., 1994). These behavioral tendencies are supported at least in part by shifts in attributions associated with the emotion of anger: anger has been shown in experiments to increase perceptions that others are responsible for negative states, decrease perceptions of risks, increase heuristic processing, and increase preferences for punitive or aggressive policies or actions (Bodenhausen et al., 1994; Goldberg et al., 1999; Keltner et al., 1993; Lerner \& Keltner, 2001; Lerner et al., 1998, 2003). Indeed, the idea that anger induced by political or economic grievances is a powerful mobilizing tool is grounded in many foundational theories of mass mobilization (Bratton \& Van de Walle 1992; Gurr, 1970; Pearlman, 2013; Scott, 1990). For all of these reasons, I expected that an anger appeal would ultimately generate more pro-opposition action than an enthusiasm appeal (Prediction 1$)^{2}$

In addition to this overall prediction, the literature on emotions and decisionmaking suggests that anger appeals might be especially effective in particular circumstances. Emotional appeals are ultimately only attempts to induce a particular emotion that may be more or less successful depending on the characteristics of the recipient or circumstances of the appeal. Anger is believed to stem from underlying "cognitive appraisals" that may resonate to different degrees with different groups: that the individual has been blocked from attaining an important goal, that the cause of that frustrated goal is an external agent's illegitimate action, and a sense of personal control or coping ability (Berkowitz \& Harmon-Jones, 2004; Lerner \& Keltner, 2000; Richard, 1991; Smith \& Ellsworth, 1985). When an anger appeal activates these appraisals, it should succeed in inducing anger in its recipient; when it does not, it could actually induce sadness, fear, or despair. This implies that anger appeals may be particularly effective in mobilizing people for whom these underlying appraisals are most likely to resonate, and when combined with other messaging that reinforces the appraisals.

One characteristic that might make it more likely that an anger appeal resonates is socioeonomic status. One of the core cognitive appraisals underlying the emotion

\footnotetext{
2 These hypotheses were pre-registered with the EGAP design registry in March 2015 before the first treatments were sent out. An update with more detailed descriptions of the analyses was added before the researcher obtained the data in May 2015. The pre-registration document can be downloaded at http:// egap.org/registration/741.
} 
of anger is a sense of personal control or coping ability. When individuals believe that they are unable to cope with a negative situation, then they should be more likely to react with fear instead of anger (Bandura, 1988). An obvious factor shaping individual coping ability - both real and perceived-is socioeconomic status (SES). Higher-SES individuals might be particularly likely to react to an anger appeal with anger and action because they are more likely to judge that they are actually able to effectively cope with the negative situation being highlighted in the appeal. In addition, higher SES over the course of a lifetime may be associated with psychological characteristics that make individuals more likely to react angrily in a negative situation (Bandura, 1982). This logic suggests that the anger appeals would have a larger impact in areas with higher socioeconomic status (Prediction 2).

A second demographic characteristic that might shape the effectiveness of anger appeals is the severity of the threat of state repression. Individuals in areas where state repression is more prevalent may harbor stronger grievances against the ruling party and thus be more likely to adopt the appraisals that the economic failures highlighted in the anger appeals are in fact due to the willful, illegitimate acts of the ruling party. In addition, anger may have a particularly powerful effect on political participation to the extent that it enables action by reducing the perceived risk of repression (Lerner \& Keltner, 2001). The perceived risk of repression should be particularly high in places where opposition supporters have actually faced repression in the past, whereas in places that have experienced no repression, the risk of repression may not be a real constraint on pro-opposition participation. Thus, I expected that anger appeals would have an even larger impact in areas that have experienced more past repression (Prediction 3). ${ }^{3}$

Finally, anger appeals might be particularly effective in conjunction with messages that reinforce their underlying appraisals. Many emotional appeals also contain messages that emphasize personal efficacy, power, or control (Tannenbaum et al., 2015). In the case of anger appeals, messages that further reinforce appraisals of personal control or coping ability might increase the likelihood that the viewer actually feels anger instead of demobilizing negative emotions like sadness or fear. Thus, I expected that the anger appeal would be more effective in conjunction with messages that emphasize personal power and control (Prediction 4).

\section{The Zimbabwean Context}

Since gaining independence in 1980, Zimbabwe has held regular, contested elections but these have not resulted in a peaceful transition of power. The ruling party ZANU-PF, which has been in power for the past 40 years, grew out of the

\footnotetext{
${ }^{3}$ It is also worth noting that it is plausible that the conditional effects of SES and past exposure to repression could cut in the opposite direction depending on which of the cognitive appraisals underlying anger they activate. Lower SES may increase the effectiveness of the anger appeal by boosting the resonance of the grievance appraisal, and more past exposure to violence may facilitate a higher appraisal of one's ability to cope in negative circumstances. These conditional effects should be tested more precisely in future research.
} 
independence struggle and enjoyed high initial popular support that diminished in the 1990s (LeBas, 2011). In 1999, a viable opposition movement emerged and dealt ZANU-PF a surprise loss in a constitutional referendum. For the past 20 years, politics in Zimbabwe has revolved around competition between ZANU$\mathrm{PF}$ and the main opposition party the Movement for Democratic Change (MDC). Various splinter parties have emerged from these two major parties and have almost always either disappeared or re-integrated into their parent parties.

ZANU-PF has been able to remain in power through a variety of tactics. Its ability to maintain control is thanks in part to legitimate appeals to voters, including its liberation struggle credentials and some popular policies such as a redistributive land reform program. However, in periods when popular support has eroded, ZANU-PF has politicized the resources of the state to use in clientelistic transactions and has relied heavily on the threat of repression through state security forces and state-aligned civil society groups.

There have been three major episodes of state repression in post-independence Zimbabwe. First, shortly after independence in the 1980s, ZANU-PF deployed the newly created armed forces into the Matabeleland region, whose inhabitants had supported a rival liberation movement and were seen as a threat to the new state. As many as 20,000 Zimbabweans were killed by the government during this period (CCJPZ, 1997). Second, after the emergence of the MDC, ZANU$\mathrm{PF}$ began using the security forces and a range of party-affiliated social groups to repress opposition candidates, organizers, and supporters (LeBas, 2006; Sachikonye, 2011). This wave of repression peaked in 2008, when the MDC won the first round of the presidential election and cost ZANU-PF its legislative majority (Bratton \& Masunungure, 2008; Human Rights Watch, 2008). After 2008, a "Government of National Unity" was formed out of negotiations with the international community, and the MDC's popular support began to weaken as the economic crisis receded. State repression receded between 2008 and 2018, and ZANU-PF won large parliamentary majorities in elections in 2013 and 2018 without widespread pre-election violence. However, the 2018 elections ushered in a third phase of active repression, as a new, less adept ZANU-PF president who came into power in a 2017 military coup has relied heavily on the security forces to quash post-election and economic protests (Beardsworth et al., 2019).

This study took place during a period of low repression and opposition fragmentation in the wake of the MDC's weak performance in the 2013 elections. Transform Zimbabwe (TZ) is run by a former MDC youth leader, and staffed by many former MDC activists. In 2017, TZ re-merged with the main MDC faction to compete in the 2018 elections under the banner of the "MDC Alliance." At the time of this study, TZ was building grassroots structures and competing in byelections to fill empty parliamentary seats.

The MDC and MDC-aligned opposition parties like TZ have historically used both positive and negative campaign messages, often invoking the emotions of enthusiasm and anger, to mobilize voters. The opposition has long had a strong, albeit somewhat general, positive policy platform. The MDC and TZ both emphasize a moderate social democratic policy platform that includes increasing access to education and health services (Zamchiya, 2013). Some analysts, however, have 
argued that this broad positive economic platform fails to mobilize Zimbabwean voters (Makgetlaneng, 2005; Southall, 2013). TZ also uses a significant amount of religious (Christian) messaging in their positive appeals. In addition to these positive messages, the opposition has a long history of using the ruling party's economic failings to mobilize voters. Economic demonstrations, strikes, stayaways, and food riots led by the Zimbabwe Congress of Trade Unions (ZCTU) in the 1990s laid a critical foundation for the formation of the MDC (McCandless, 2011). Protests around economic grievances including price increases and electoral irregularities have continued to play a pivotal role in the opposition's strategy for mobilizing voters. In the years prior to this experiment, $\mathrm{TZ}$ also frequently used direct attacks on the ruling party for corruption and economic mismanagement in its speeches and communications with its supporters.

\section{Research Design}

Estimating the causal impact of emotional appeals on political mobilization in a repressive environment is difficult for a number of reasons. First, identifying the causal impact of emotions requires exogenous variation in exposure to emotional appeals. Without exogenous variation, it is impossible to isolate the effect of the emotional appeal from factors that might drive supporters to select into exposure. In this case, I use random assignment of opposition supporters to different emotional appeals to identify the impact of emotions on action.

Second, isolating the effect of emotions requires that the information in the messages be held constant. Importantly, the need to hold information constant implies that the anger messages must be compared to a placebo message instead of a pure control. To hold information constant, TZ agreed to create two versions of the same ad that differed only in the images, music, and small variations in wording. In both messages, the images depict generic, common scenes that all Zimbabweans recognize such as country roads, clinics, and homesteads. The text in both versions of the appeals provides the same information about the party's position and the state of the nation.

Third, studying political participation in an electoral autocracy comes with significant ethical considerations. This project would not have been possible without the collaboration of an opposition party that was interested in empirically testing how to mobilize its supporters. TZ regularly sends out communications to its supporters and did not fundamentally change its operations during the course of this experiment; they only introduced random variation in the specific messages that went out at a given time. TZ crafted and produced the messages and created and managed the chat groups. The researcher's role was to provide information on the research design and to analyze the anonymized data. TZ's supporters voluntarily joined the WhatsApp groups with knowledge that they would be receiving political messages. To formalize this agreement, a Memorandum of Understanding was signed between the president of TZ and the provost of Columbia University that detailed each party's role and responsibilities. Because of this delimitation of roles, this research was determined not to involve human subjects by the Columbia University IRB. 
Fourth, we wanted to measure an outcome that was at once behavioral, meaningful, and within the level of risk that TZ's supporters had accepted to take when they joined the groups. Although TZ also mobilizes its supporters to engage in offline actions such as rallies, for the experiment we decided to focus on the lower-risk outcome of political speech. Opposition supporters believe that political speech, including on social media, is taken seriously by the regime. Around the time of the experiment, a meme making fun of a stumble by the nonagenarian president was being circulated, along with rumors that the police and secret service were randomly entering buses and sanctioning people if they had these images on their phones. Nevertheless, data collected by organizations tracking political violence in Zimbabwe and media reports at the time show few actual cases of citizens being targeted with sanctions for speech, particularly for speech made in private chat groups like the TZ WhatsApp groups.

\section{Description of the Treatments}

This experiment was implemented over two rounds that took place two weeks apart. The emotional appeal consisted of an image or video message that was reinforced with a text message sent out during a three-hour window. TZ decided to reiterate the image or video messages in text messages to ensure that some version of the emotional appeal reached even supporters who had limited data plans or cellular access. Messages were distributed in English with some introductory greetings in Shona or Ndebele depending on the language of the group members, according to the standard practices of the party.

During the first round, the main treatment consisted of an image or video that presented an issue, namely infrastructure or health, in either a positive or negative light. Appendix Figure A2 displays the content of the images used in the first round. During the second round, the treatment was a dramatic video that depicted a story of a grandmother seeking treatment for her sick granddaughter. In the anger version of the video, the grandmother brings her granddaughter to a rural clinic with no medicine, and then the truck she is traveling in breaks down in a pothole on the way to a district hospital. At the hospital the grandmother waits for a long time and then loses her spot to a man who bribes the nurse. In the enthusiasm version of the video, presented as the Zimbabwe of the future, the granddaughter gets treated by a nurse at the rural clinic and then travels by car to the district hospital. She is treated there by a professional nurse and in the last scene comes home healthy from school the next day. Figures A3 and A4 in the Appendix shows screenshots of the anger and enthusiasm videos that were used in round two. In both rounds the treatments were followed up with a message asking the group members "Are you angry/hopeful yet? Join Transform Zimbabwe today!"

The emotional appeal was cross-randomized with a second treatment designed to reinforce one of the appraisals believed to underlie anger in a factorial design. Specifically, half of the groups that received the anger appeal and half of the groups that received the enthusiasm appeal also received a greeting message that included the 

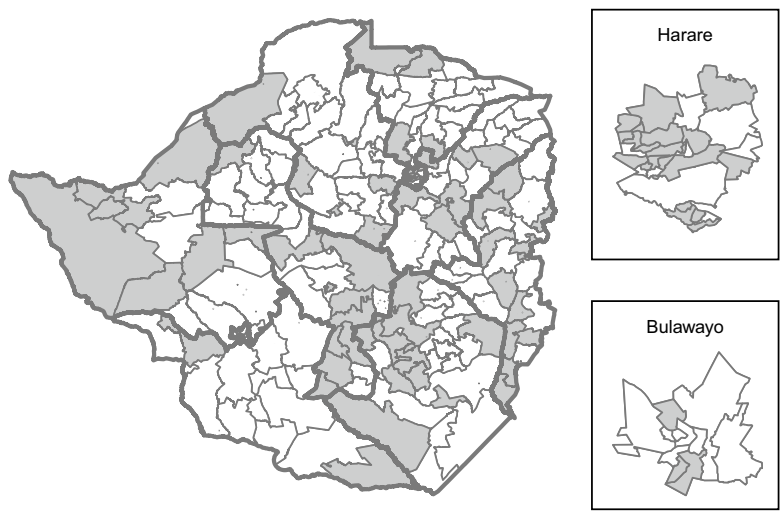

Fig. 1 Constituencies where TZ has WhatsApp groups

sentence: "We have the power to transform Zimbabwe!" to reinforce the appraisal of personal agency. The rest of the groups received the control version of this second treatment, an introductory message that ended with the sentence "Our transformation has been held back for too long!"

\section{Randomization and Implementation}

WhatsApp groups were block randomized using an R script based on the province and size (above or below the province's median group size). For both rounds, randomization was carried out a few hours before the messages were sent out. Appendix Table A1 shows that there are no indications of a breakdown of randomization procedures.

The messages were sent out to $929 \mathrm{TZ}$ supporters who had joined a total of 85 groups in two rounds: 703 supporters in 64 groups in the first round on March 20, 2015, and 929 supporters in 85 groups in the second round on April 3, 2015. Figure 1 shows in red that TZ had constituency-level WhatsApp groups that were part of the experiment in every province in Zimbabwe.

The activity in the groups was monitored for $24 \mathrm{~h}$ before and after the messages were sent out. It was anonymized and shared with the researcher for analysis. I chose $24 \mathrm{~h}$ as the window to measure outcomes to balance concerns that network coverage gaps could delay some groups from getting the messages immediately, and a desire to identify the immediate emotional response to the appeals.

There was some noncompliance due to administrative difficulties within the TZ communications team. Ten of the 150 groups in the experiment (5 assigned to treatment and 5 assigned to control) received some but not all of the treatment. Two groups assigned to the treatment received the control version of the messages, and one group received both the treatment and control versions of the messages. Anecdotally, some individuals within the groups could not access the appeals due to network failures or having run out of data on their accounts. 


\section{Empirical Strategy and Estimation}

\section{Main Effects}

To test the main hypothesis that the anger appeal would generate more participation than the enthusiasm appeal, I estimate the intent-to-treat (ITT) effect using OLS. I include block fixed effects in all specifications, and in some specifications also include controls for the size of the group, pre-treatment measures of the outcome, and the constituency's past exposure to political violence and level of poverty (described in more detail in "Heterogeneous Effects" section) to increase precision. 4 I use inverse propensity score weights to account for the fact that not every unit had an equal probability of being assigned to treatment.

As indicators of pro-opposition participation, I measured how TZ's supporters responded to the messages with four different metrics:

\section{Number of messages sent.}

2. Number of supporters who participated.

3. Number of party slogans ("Viva!").

4. Number of party symbols (a V-for-victory sign).

The first two indicators - number of messages and number of participants-can be considered reflections of the quantity of the response to the messages. The last two-number of times supporters responded with the party slogan and the number of times they sent the party symbol-reflect the level of enthusiasm of participants. The primary hypothesis test is based on a mean effects index using all four operationalizations of political participation.

Figure 2 shows an anonymized transcript of one of the groups assigned to the anger condition. You can see in this transcript that the participants speak in a mix of English and local languages, abbreviations and slang, and how they use the slogan "viva" and the "v for victory" party symbol to express enthusiasm.

Text shared by a multi-lingual groups in social media chat groups has characteristics that make pre-processing difficult. For instance, participants often use variation in spelling to signal levels of enthusiasm: writing "vivaaaaa" in this context communicates more excitement than "viva." Typical text processing steps like stemming words is not possible when some words are written without punctuation and some words are written without spaces: for example, in the transcript, "hwzt" replaces "how is it?" Emoticons were processed as unicode. For all of these reasons, I limited the preprocessing of the text to simply making everything lower case and chose metrics that depend little on the language being used. "Viva" is the party slogan in every language and is interspersed in text written in English, Shona, Ndebele, and Tonga.

\footnotetext{
4 These controls were selected because they are likely to explain variation in post-treatment outcomes. The size of the group and pre-treatment outcome measures are group-specific predictors of the overall level of group activity. Past political violence and poverty levels calculated at the constituency level have been theoretically linked to a constituency's level of pro-opposition mobilization.
} 


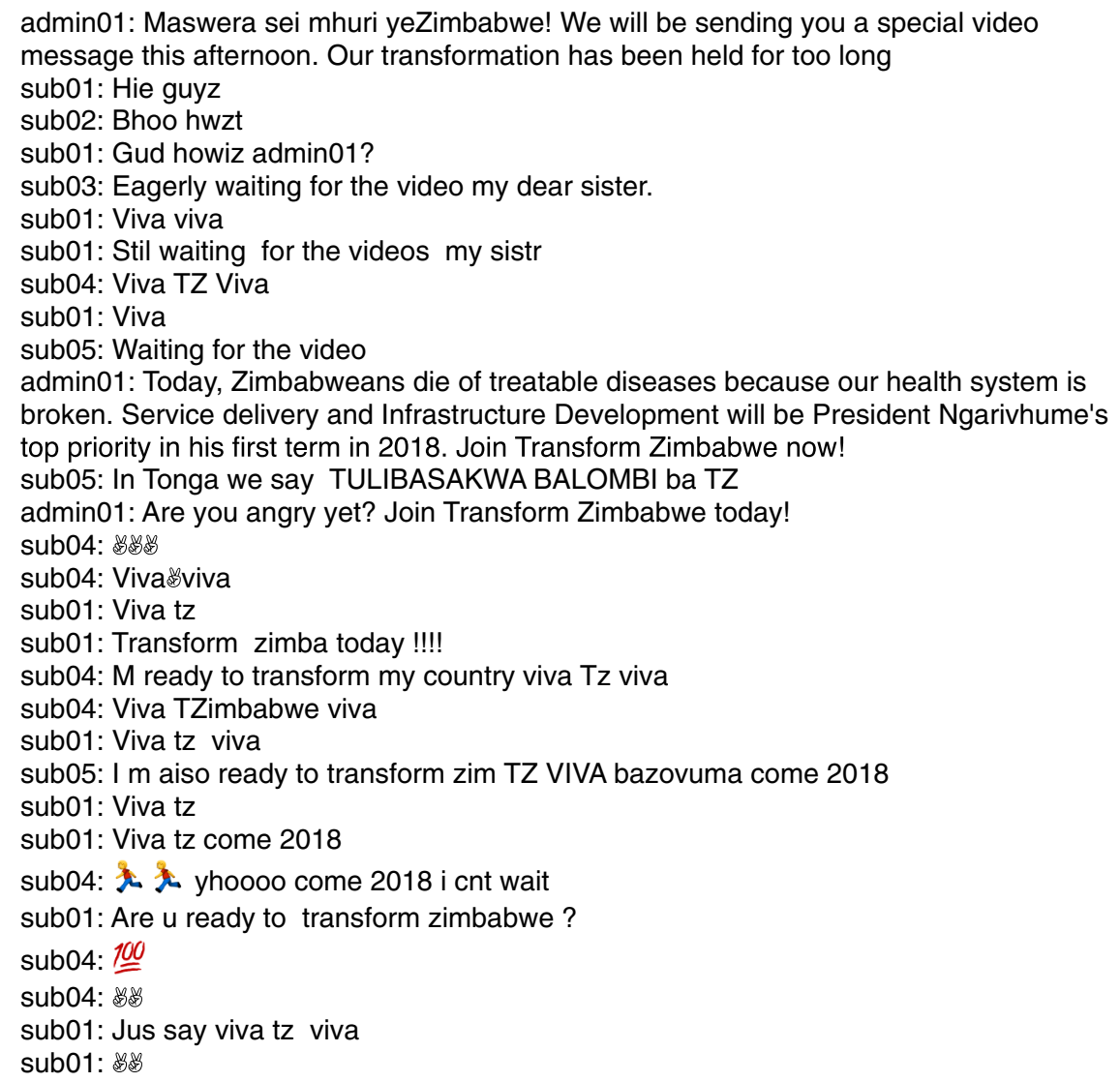

Fig. 2 Example transcript

The number of messages and participants is also independent of language or the balance of slang and formal text. ${ }^{5}$

I also tracked whether the party received donations from each constituency via mobile money transfer. However, because cash donations are not a standard practice in Zimbabwean politics, in the pre-analysis plan I included a condition that if fewer than 20 donations in total were made in the $24 \mathrm{~h}$ after the treatments were distributed, I would not analyze donations as an outcome. Donations did not meet this threshold, are thus are not analyzed here.

\footnotetext{
${ }^{5}$ Although I preregistered an outcome measuring the count of the number of words sent out by participants, I replaced it with the number of messages for several reasons. First, the number of words used to communicate the same idea varies across languages. Second, the number of words varies based on the amount of slang used. Third, many words are run together because of typos: for example, "Viva[symbol] viva" in the transcript would be counted as one word due to lack of spacing. Therefore, it is ambiguous whether excitement would be signaled by more or fewer words if excited participants speak more in their native language, slang, abbreviations, or typos.
} 
Finally, as a manipulation check, I had two Zimbabwean researchers code the messages from participants for their level of anger, enthusiasm, sadness, and fear. If the anger appeals worked as intended, they should have elicited an anger response from some or all of the party's supporters. Both messages included elements intended to elicit enthusiasm for the party, so I did not necessarily expect to see differences across the two appeals in the level of enthusiasm induced. I also measured sadness and fear as non-targeted emotions that may nevertheless have been differentially induced by the two versions of the emotional appeals.

\section{Heterogeneous Effects}

The remaining three hypotheses made predictions about where the anger appeal would have the largest effect relative to the enthusiasm appeal. I test for these heterogeneous effects using the following specification:

$$
Y_{t=1}=\tau_{1} Z_{\text {anger }} \times X_{\text {poverty }}+\tau_{2} Z_{\text {anger }} \times X_{\text {violence }}+\tau_{3} Z_{\text {anger }} \times Z_{\text {power }}+\gamma Y_{t=0}+\theta X_{\text {controls }}+\epsilon
$$

where $Z_{\text {anger }}$ is a dummy variable indicating assignment to the anger appeal, and $Z_{\text {power }}$ is a dummy indicating assignment to the message emphasizing personal power. The coefficients on the interaction term $Z_{\text {anger }} \times X_{\text {poverty }}$ represents the differential impact of the anger treatment in areas with varying levels of poverty and the coefficient on $Z_{\text {anger }} \times X_{\text {violence }}$ represents the differential impact of the anger treatment in areas that experienced violence in the 2008 elections. $Y_{t=1}$ is the post-treatment measure of the relevant outcome, while $Y_{t=0}$ is a pre-treatment measure of the outcome of interest. $X_{\text {controls }}$ includes the direct effects of all of the components of the interaction terms (the two treatments, poverty, and past violence), as well as the number of members in each group and block fixed effects.

To measure past exposure to violence, I use data collected by a civil society group called Sokwanele from the 2008 electoral crisis, the last major episode of electoral violence that the country had experienced as of 2015. Sokwanele's data is collected from reports of citizens and service providers for victims of political violence. I use a binary indicator that takes a value of 1 if a constituency reported any violence in 2008. Violence in Fig. 3 is shown in its original continuous version, with the darkest grey representing the most violent constituencies and white representing constituencies that reported no violence in 2008 to Sokwanele. In the analyses that follow this measure of violence is dichotomized to reduce the risk of bias from measurement error.

To measure poverty, I use the anthropogenic data of children under five from the most recent Demographic and Health Survey (DHS), averaged for all the enumeration areas within the constituency boundaries that were used to define the WhatsApp 
(a) Violence in 2008 (Sokwanele)

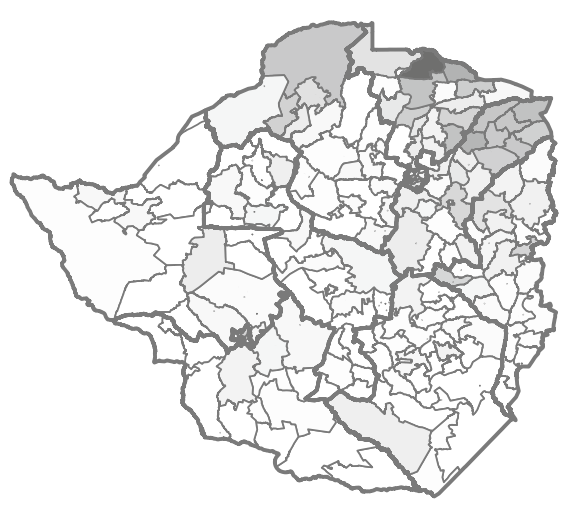

Violent Events

(b) Poverty in 2012 (DHS)

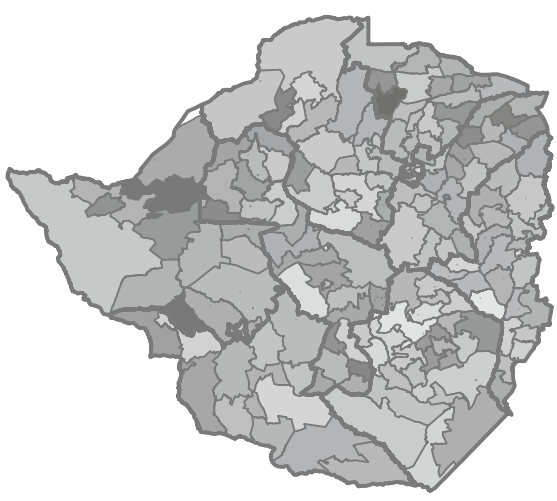

Weight-for-height z-score
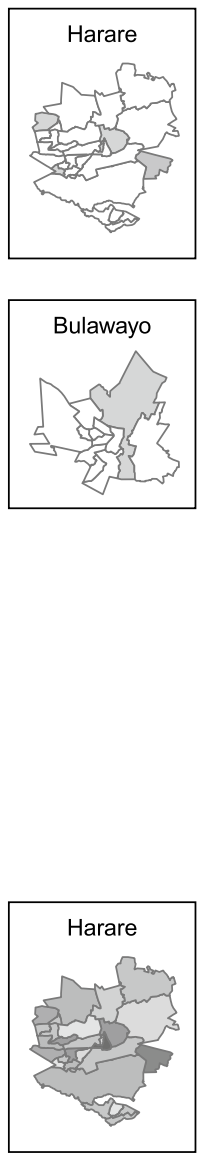

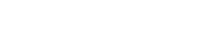


Table 1 The anger appeal induced angrier responses than the enthusiasm appeal

\begin{tabular}{|c|c|c|c|c|c|c|c|c|}
\hline & \multicolumn{8}{|c|}{ Dependent variable } \\
\hline & \multicolumn{2}{|l|}{ Anger } & \multicolumn{2}{|c|}{ Enthusiasm } & \multicolumn{2}{|c|}{ Sadness } & \multicolumn{2}{|l|}{ Fear } \\
\hline & (1) & (2) & (3) & (4) & (5) & (6) & (7) & (8) \\
\hline Anger appeal & $\begin{array}{l}0.04 * * * \\
(0.02)\end{array}$ & $\begin{array}{l}0.03^{* *} \\
(0.01)\end{array}$ & $\begin{array}{l}0.13 * * \\
(0.06)\end{array}$ & $\begin{array}{l}0.13 * * \\
(0.06)\end{array}$ & $\begin{array}{l}0.03 \\
(0.03)\end{array}$ & $\begin{array}{l}0.03 \\
(0.03)\end{array}$ & $\begin{array}{l}0.02 \\
(0.01)\end{array}$ & $\begin{array}{l}0.01 \\
(0.01)\end{array}$ \\
\hline Log(group size) & & $\begin{array}{l}0.01 \\
(0.01)\end{array}$ & & $\begin{array}{l}0.10^{*} \\
(0.06)\end{array}$ & & $\begin{array}{l}-0.01 \\
(0.02)\end{array}$ & & $\begin{array}{l}0.01 \\
(0.01)\end{array}$ \\
\hline Any violence & & $\begin{array}{l}-0.01 \\
(0.02)\end{array}$ & & $\begin{array}{l}-0.05 \\
(0.08)\end{array}$ & & $\begin{array}{l}0.01 \\
(0.04)\end{array}$ & & $\begin{array}{l}0.01 \\
(0.02)\end{array}$ \\
\hline Poverty & & $\begin{array}{l}-0.001 * * \\
(0.0002)\end{array}$ & & $\begin{array}{l}0.002 * \\
(0.001)\end{array}$ & & $\begin{array}{l}-0.001 * * \\
(0.0004)\end{array}$ & & $\begin{array}{l}0.0000 \\
(0.0002)\end{array}$ \\
\hline Block FE & $\checkmark$ & $\checkmark$ & $\checkmark$ & $\checkmark$ & $\checkmark$ & $\checkmark$ & $\checkmark$ & $\checkmark$ \\
\hline Constant & $\begin{array}{l}-0.02 \\
(0.06)\end{array}$ & $\begin{array}{l}-0.05 \\
(0.06)\end{array}$ & $\begin{array}{l}0.44 * \\
(0.22)\end{array}$ & $\begin{array}{l}0.55^{* * *} \\
(0.25)\end{array}$ & $\begin{array}{l}0.11 \\
(0.09)\end{array}$ & $\begin{array}{l}0.02 \\
(0.11)\end{array}$ & $\begin{array}{l}-0.01 \\
(0.05)\end{array}$ & $\begin{array}{l}-0.02 \\
(0.06)\end{array}$ \\
\hline Observations & 150 & 148 & 150 & 148 & 150 & 148 & 150 & 148 \\
\hline $\mathrm{R}^{2}$ & 0.32 & 0.37 & 0.36 & 0.41 & 0.35 & 0.39 & 0.12 & 0.12 \\
\hline
\end{tabular}

Robust standard errors in parentheses

The unit of analysis is the WhatsApp group. ITTs are estimated using OLS with inverse propensity weights

${ }^{*} p<0.1 ;{ }^{* *} p<0.05 ; * * * p<0.01$

groups. ${ }^{6}$ My measure of poverty is the weight-for-height $z$-scores of children under five averaged by constituency; constituencies that are shaded in darker grey on the map have a lower average weight.

Figure 3 show maps of the distribution of exposure to violence and poverty.

\section{Results}

\section{Manipulation Check}

Did the anger appeal actually increase expressions of anger? Did it also increase expressions of enthusiasm more than the purely enthusiastic appeal, or increase expressions of non-targeted negative emotions? Each message was coded by two different native Shona speakers who were blinded to the treatment status of the groups.

\footnotetext{
${ }^{6}$ Most of the constituencies (136 out of 150) can be matched with 2012 data, but for 14 constituencies 2005 DHS data is the most recent available.
} 
The inter-rater reliability (IRR) for anger, fear, and sadness ranged between 92 and $97 \%$, while IRR for enthusiasm was $63 \%{ }^{7}$

Table 1 shows that the anger appeal significantly increased the proportion of messages expressing anger sent by participants in the WhatsApp groups compared to the enthusiasm appeal. Substantively, supporters in groups assigned to the anger appeal sent 3-4 percentage points more messages that were coded by at least one of the two coders as expressing anger. In addition, the anger appeal caused more enthusiastic responses: 13 percentage points more of the responses in groups assigned to the anger appeal were coded as enthusiastic by one of the coders. This should not be interpreted as a manipulation failure given that both appeals were also designed to induce enthusiasm for TZ. By contrast, there was no significant increase in expressions of fear or sadness, suggesting that the anger appeal successfully targeted anger instead of other negative emotions.

\section{Main Effects}

This section presents the results of tests of the primary substantive hypothesis: did the anger appeal cause more pro-opposition participation in the WhatsApp groups? Table 2 presents the ITTs for the full mean effects index and the four individual components that went into it.

Table 2 shows that the anger appeal induced significantly more pro-opposition participation in the WhatsApp groups, in line with Prediction 1. The mean effects index, which gives equal weight to the four standardized subcomponents measured over the $24 \mathrm{~h}$ following the treatments, is $0.36-0.38$ standard deviations higher for groups assigned to the anger appeal than those to the enthusiasm appeal. This overall result is significant at the $5 \%$ level. Based on this test, we can conclude that the anger messages were significantly more effective in generating participation than the purely enthusiastic messages. This overall increase in participation is consistent across the four measures, although the increases are only statistically significant for the number of symbols $(p=0.03)$ and participants $(p=0.07)$. Substantively, the differences are large, representing a $30 \%$ increase in the number of participants and a $173 \%$ increase in the use of party symbols.

Is this result dependent on the specific period of time used to calculate the outcome variables? While the hypothesis tests in Table 2 were based on the level and quality of participation in the $24 \mathrm{~h}$ after the treatments were sent out to each group, we can also test for robustness to various time periods by creating increasingly large windows of time around the treatment in 3-h increments and estimating the ITT within each window. Figure 4 shows that the effect is consistent over time.

Importantly, the effects calculated here represent the difference between the anger appeal and the enthusiasm appeal instead of a pure control group. This holds constant the information that the groups received and thus isolates the

\footnotetext{
7 It appears that the lower IRR on enthusiasm is a function of the two coders have different thresholds for what was sufficiently enthusiastic: one coder identified $46 \%$ of the messages as enthusiastic, while the other found that $81 \%$ met the threshold to be coded as enthusiastic.
} 


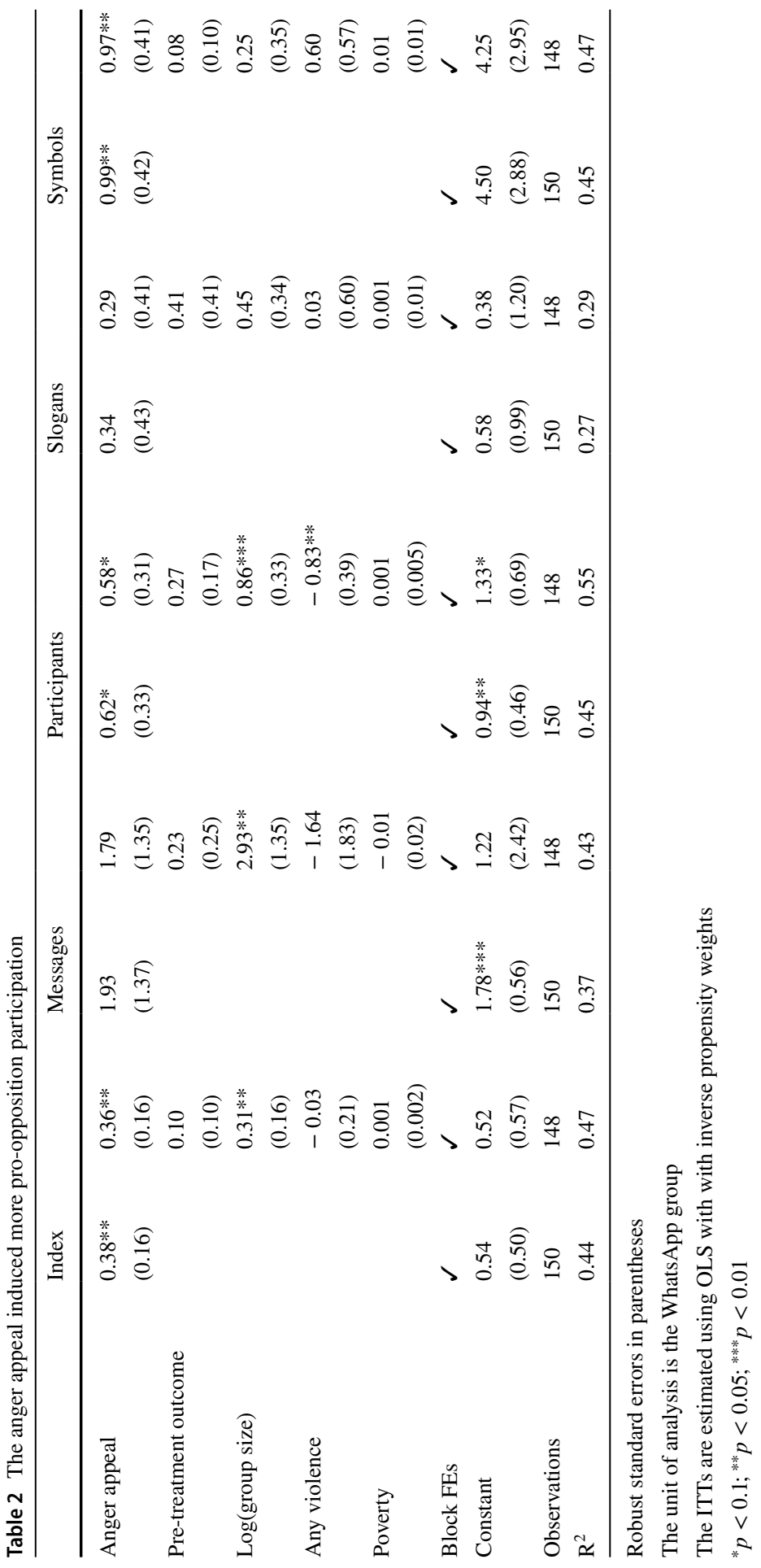


Fig. 4 ITTs at different time cutpoints-Mean Effects Index

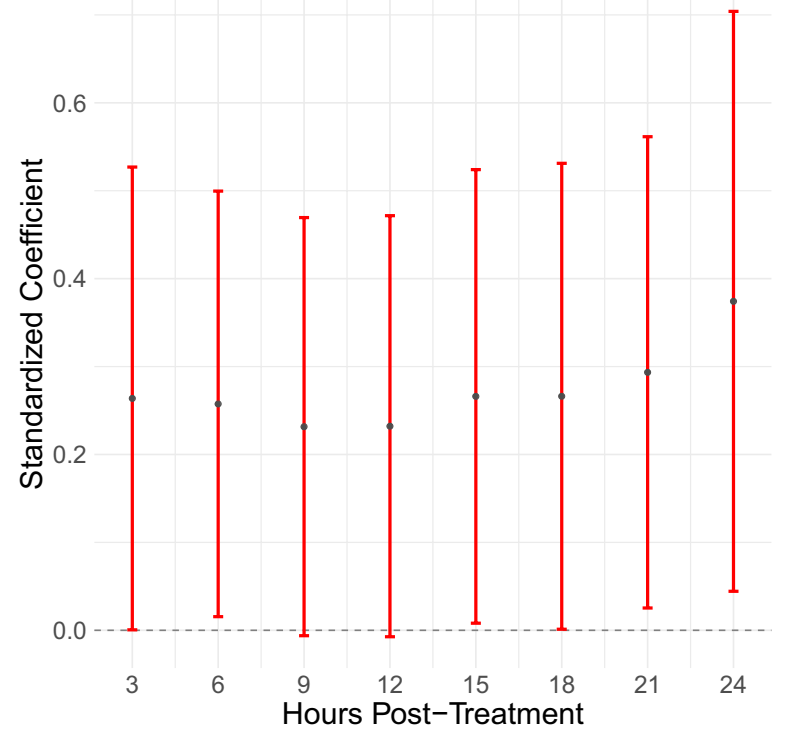

(b) Poverty

(c) Power Treatment
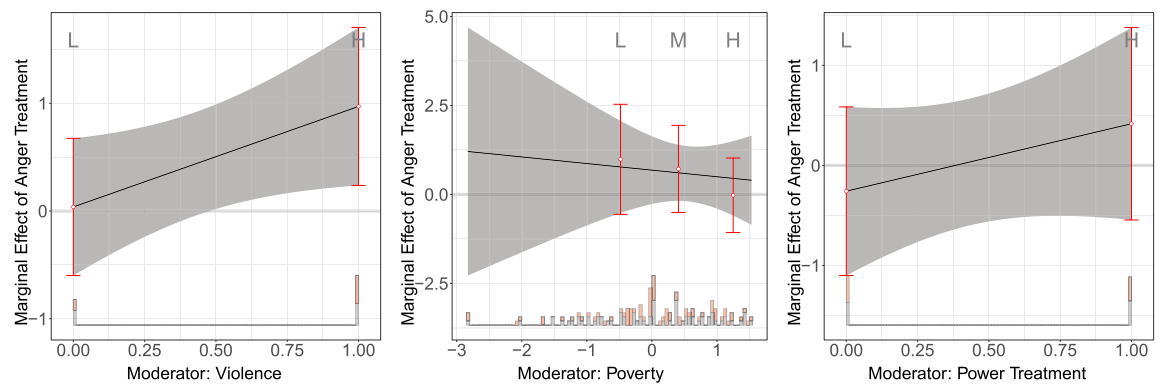

Fig. 5 Marginal effects by previous violence, poverty, and the power treatment-Mean Effects Index

effect of the emotional valence of the appeal, but it also implies that the difference is driven by the relative effects of the two treatments. The fact that both treatments were followed by large immediate increases in all four outcome indicators (shown in Appendix Figure A1) is suggestive evidence that both were effective in increasing pro-opposition participation such that the estimates capture the increased effectiveness of the anger appeal. 


\section{Heterogeneous Effects}

Next I test three hypotheses about where the effects of the anger appeals might be largest. First, the effect of the anger appeal might be even larger in high-income areas if higher-income people are more likely to respond to negative situations with anger rather than fear (Prediction 2). Second, areas affected by more violence may be more susceptible to the anger appeal through its potential effect on perceptions of risks and past grievances (Prediction 3). Third, the Appraisal Tendency Framework suggests that the anger appeal should work best in conjunction with messages that emphasize personal power (Prediction 4).

In this section I present figures showing the marginal effects of the anger appeal relative to the enthusiasm appeal at different levels of violence, poverty, and assignment to the power appraisal treatment. All continuous measures are standardized. Appendix Table A3 presents the full results.

Figure 5 show the marginal effects of the anger appeal at different levels of poverty, whether or not the constituency reported any violence around the 2008 election according to the Sokwanele data, and whether the group was assigned to the second power appraisal treatment. These marginal effects plots also include the control variables described in "Empirical Strategy and Estimation" section.

There are no statistically significant heterogeneous effects of the anger treatments based on the level of violence that a constituency reported in 2008, level of poverty as per the most recent DHS data, or assignment to the power appraisal treatment. The null findings on the constituency's characteristics suggest that anger appeals are effective in a broad swathe of constituencies, contrary to Predictions 2-3. However, they should be interpreted with some caution given that the data used to test these hypotheses is at the constituency rather than group level, creating an ecological inference problem, and was collected several years prior to this experiment. The fact that the anger appeal is not more effective when paired with a message designed to reinforce the anger-aligned appraisal of personal power is evidence against Prediction 4. It is possible that instead of reinforcing the anger appeal the personal power message substitutes for it: indeed, on one of the four outcomes, the power message has a positive and significant effect for groups assigned to the enthusiasm appeal. It is also possible that this treatment - a single text message sent along with several others-was too weak to have the intended effect, particularly in comparison with emotionally gripping music, stories, and images. These predictions about the conditions in which anger appeals should be most effective should be subjected to more rigorous testing in the future.

\section{Conclusion}

Millions of citizens speak out against non-democratic regimes despite the risk of reprisals. How do opposition parties mobilize citizens in non-democratic settings? I argue that emotional appeals invoking anger play a role in overcoming the collective action dilemma that opposition supporters face. Theory from psychology predicts that anger should make individuals more likely to take action through a number of 
channels, including by influencing how individuals perceive risks and their level of inhibition. This implies that opposition parties that can craft effective anger appeals may be able to induce higher levels of participation, at least in the short term.

This study tests whether and when appeals that invoke anger rather than enthusiasm are more effective in mobilizing opposition supporters to participate online in a repressive environment. In order to identify the causal effect of anger appeals, I analyze an experiment run by a Zimbabwean opposition party that tested the effectiveness of campaign messages with the same informational content but different emotional valences. This research design enables a test of opposition mobilization that identifies the casual role of emotional appeals over social media on a behavioral measure of political action.

The results are in line with the expectation that anger over economic grievances can be harnessed by opposition movements to mobilize their supporters. The anger appeal induced significantly more expressions of support for the opposition party than the pure enthusiasm appeal. These differences are substantively meaningful, representing between 30 and $170 \%$ increases over the enthusiasm groups across four measures of participation. The anger appeal was more effective across many types of constituencies, not only those with the most capacity to take action or the strongest political grievances.

Why was the anger appeal more effective? The most straightforward explanation, and one in line with the results of the manipulation check based on the text of the WhatsApp messages, is that it succeeded in its goal of inducing more anger than the enthusiasm appeal. However, a few other explanations are also plausible. First, the manipulation check also showed that the anger appeal induced more enthusiasm than the purely enthusiastic appeal. Second, it is possible that the anger appeals, which focused on the gap between expectations and reality in Zimbabwe, may have primed a higher tolerance for risk by putting TZ supporters in the domain of losses. Future research, perhaps using lab experimental methods that enable more refined measurement, could try to separately parse out these mechanisms. In this case, given that all of the informational content of the two versions of the appeals were the same, the greater levels of enthusiasm and any potential effects on loss aversion could be inseparable downstream effects of anger.

These findings suggest that the mobilizing strategies of opposition parties and activists matter, and that more confrontational, grievance-based strategies can be particularly effective in mobilizing immediate participation. Scholars have long emphasized that political entrepreneurs can mobilize risky forms of participation using grievance appeals. The findings also support a more nuanced view of the role of ICT in facilitating expressions of dissent. While much of the literature on ICT has emphasized its importance in spreading information or lowering the cost of coordination among opposition members, this study suggests that the emotional content disseminated via ICT can also have a potent mobilizing effect.

Might these findings extend to participation in higher stakes forms of political participation, such as protest attendance or pro-opposition voting? Some have criticized online political participation as "slacktivism" and argued that it crowds out participation in more traditional forms of collective action. However, recent research suggests that online communications in non-democratic settings can spur offline 
political participation (Larson et al., 2019; Steinert-Threlkeld et al., 2015). Recent observational work has found that the expansion of access to technology such as cell phone networks caused increases in participation in protest (Manacorda \& Tesei, 2020; Christensen \& Garfias, 2018), and that receiving information about protest via social media is associated with intentions to participate in offline forms of protest (LeBas \& Young, 2020). Part of the mechanism linking online participation to offline action in non-democratic settings may be that online participation builds second-order beliefs about pro-opposition action, breaking patterns of preference falsification (Kuran, 1991, 1995). Opposition political parties like Transform Zimbabwe need to convince skeptical supporters that they have enough latent support to unseat an entrenched, authoritarian incumbent. Demonstrating that they are able to mobilize citizens by engaging them in acts of collective political participation is a logical way to build that credibility.

What should opposition parties operating in non-democratic environments draw from these results? Clearly, anger appeals can be a powerful mobilizing force. However, these results do not suggest that opposition parties can maximize engagement by only invoking anger. First, it is important to note that the anger appeals both highlighted the service delivery failures of an incumbent regime, and reminded supporters that they could provide a better alternative. Second, the results in this article show that anger appeals work for a subset of supporters who are already fairly committed to a political party. Anger appeals may be less effective in mobilizing citizens who are less ideologically aligned with the opposition or more reluctant to take action. Finally, it is plausible that anger appeals may lose their potency and even cause supporters to become fatigued or disaffected if used frequently. A conservative interpretation of the results of this experiment is that anger appeals can have powerful short-term mobilizing effects in conjunction with a credible positive message. Anger appeals are thus not an alternative but probably a complement to the longer-term work of building a positive party identity and grassroots mobilizing structure.

Supplementary Information The online version contains supplementary material available at https://doi. org/10.1007/s11109-021-09711-z.

Acknowledgements This study was supported by Directorate for Social, Behavioral and Economic Sciences (Grant No. 153077), United States Institute of Peace and International Peace Research Association Foundation.

Open Access This article is licensed under a Creative Commons Attribution 4.0 International License, which permits use, sharing, adaptation, distribution and reproduction in any medium or format, as long as you give appropriate credit to the original author(s) and the source, provide a link to the Creative Commons licence, and indicate if changes were made. The images or other third party material in this article are included in the article's Creative Commons licence, unless indicated otherwise in a credit line to the material. If material is not included in the article's Creative Commons licence and your intended use is not permitted by statutory regulation or exceeds the permitted use, you will need to obtain permission directly from the copyright holder. To view a copy of this licence, visit http://creativecommons.org/licen ses/by/4.0/. 


\section{References}

Albertson, B., \& Gadarian, S. K. (2015). Anxious politics: Democratic citizenship in a threatening world. Cambridge University Press.

Bandura, A. (1982). Self-efficacy mechanism in human agency. American Psychologist, 37(2), 122.

Bandura, A. (1988). Self-efficacy conception of anxiety. Anxiety Research, 1, 77-98.

Barberá, P., Wang, N., Bonneau, R., Jost, J. T., Nagler, J., Tucker, J., \& González-Bailón, S. (2015). The critical periphery in the growth of social protests. PLOS ONE, 10(11), e01436e0143611.

Barrett, L. F., \& Russell, J. A. (1999). The structure of current affect: Controversies and emerging consensus. Current Directions in Psychological Science, 8(1), 10-14.

Beardsworth, N., Cheeseman, N., \& Tinhu, S. (2019). Zimbabwe: The coup that never was, and the election that could have been. African Affairs, 118(472), 580-596.

Berkowitz, L., \& Harmon-Jones, E. (2004). Toward an understanding of the determinants of anger. Emotion, 4(2), 107-130.

Bodenhausen, G. V., Sheppard, L. A., \& Kramer, G. P. (1994). Negative affect and social judgment: The differential impact of anger and sadness. European Journal of Social Psychology, 24(1), 45-62.

Brader, T. (2006). Campaigning for hearts and minds: How emotional appeals in political ads work. University of Chicago Press.

Bratton, M., Bhavnani, R., \& Chen, T.-H. (2012). Voting intentions in Africa: Ethnic, economic, or partisan? Commonwealth and Comparative Politics, 50(1), 27-52.

Bratton, M., \& Masunungure, E. (2008). Zimbabwe's long agony. Journal of Democracy, 19(4), 41-55.

Bratton, M., \& Van de Walle, N. (1992). Popular protest and political reform in Africa. Comparative Politics, 24(4), 419-442.

Breuer, A., Landman, T., \& Farquhar, D. (2015). Social media and protest mobilization: Evidence from the Tunisian revolution. Democratization, 22(4), 764-792.

Bunce, V. J., \& Wolchik, S. L. (2011). Defeating authoritarian leaders in postcommunist countries. Cambridge University Press.

CCJPZ. (1997). Report on the 1980s disturbances in Matabeleland and the Midlands. Catholic Commission for Justice and Peace in Zimbabwe.

Christensen, D., \& Garfias, F. (2018). Can you hear me now? How communication technology affects protest and repression. Quarterly Journal of Political Science, 13(1), 89-117.

Enikolopov, R., Makarin, A., \& Petrova, M. (2020). Social media and protest participation: Evidence from Russia. Econometrica, 88(4), 1479-1514.

Freedom House. (2019). Freedom on the Net 2019: The crisis of social media. Technical report, Freedom House.

Frijda, N. H. (1986). The emotions. Cambridge University Press.

Frijda, N. H., Kuipers, P., \& Ter Schure, E. (1989). Relations among emotion, appraisal, and emotional action readiness. Journal of Personality and Social Psychology, 57(2), 212.

Goldberg, J. H., Lerner, J. S., \& Tetlock, P. E. (1999). Rage and reason: The psychology of the intuitive prosecutor. European Journal of Social Psychology, 29(56), 781-795.

Gurr, T. R. (1970). Why men rebel. Princeton University Press.

Harmon-Jones, E., Harmon-Jones, C., \& Price, T. F. (2013). What is approach motivation? Emotion Review, 5(3), 291-295.

Horowitz, D. L. (1985). Ethnic groups in conflict. University of California Press.

Horowitz, J., \& Klaus, K. (2020). Can politicians exploit ethnic grievances? An experimental study of land appeals in Kenya. Political Behavior, 42(1), 35-58.

Human Rights Watch. (2008). "Bullets for Each of You” State-Sponsored Violence since Zimbabwe's March 29 Elections. Technical report.

Ivarsflaten, E. (2008). What unites right-wing populists in Western Europe? Re-examining grievance mobilization models in seven successful cases. Comparative Political Studies, 41(1), 3-23.

Jasper, J. M. (2008). The art of moral protest: Culture, biography, and creativity in social movements. University of Chicago Press.

Jost, J. T., Barberá, P., Bonneau, R., Langer, M., Metzger, M., Nagler, J., Sterling, J., \& Tucker, J. A. (2018). How social media facilitates political protest: Information, motivation, and social networks. Political Psychology, 39, 85-118. 
Keltner, D., Ellsworth, P. C., \& Edwards, K. (1993). Beyond simple pessimism: Effects of sadness and anger on social perception. Journal of Personality and Social Psychology, 64(5), 740-752.

King, G., Pan, J., \& Roberts, M. E. (2017). How the Chinese government fabricates social media posts for strategic distraction, not engaged argument. American Political Science Review, 111(3), 484-501.

Kuran, T. (1991). Now out of never: The element of surprise in the east European revolution of 1989. World Politics, 44(1), 7-48.

Kuran, T. (1995). Private truths, public lies: The social consequences of preference falsification. Harvard University Press.

Larson, J. M., Nagler, J., Ronen, J., \& Tucker, J. A. (2019). Social networks and protest participation: Evidence from 130 million Twitter users. American Journal of Political Science, 63(3), 690-705.

Lazarus, R. S. (1991). Emotion and adaptation. Oxford University Press.

LeBas, A. (2006). Polarization as craft: Party formation and state violence in Zimbabwe. Comparative Politics, 38(4), 419-428.

LeBas, A. (2011). From protest to parties: Party-building and democratization in Africa. Oxford University Press.

LeBas, A., \& Young, L. E. (2020). Repression and dissent around a potential inflection point: Panel data evidence from Zimbabwe. Presented at ESOC 2020, June 2020.

LeDoux, J. (1996). The emotional brain: The mysterious underpinnings of emotional life. Simon and Schuster.

Lerner, J. S., \& Keltner, D. (2000). Beyond valence: Toward a model of emotion-specific influences on judgement and choice. Cognition and Emotion, 14(4), 473-493.

Lerner, J. S., \& Keltner, D. (2001). Fear, anger, and risk. Journal of Personality and Social Psychology, 81(1), 146-159.

Lerner, J. S., Goldberg, J. H., \& Tetlock, P. E. (1998). Sober second thought: The effects of accountability, anger, and authoritarianism on attributions of responsibility. Personality and Social Psychology Bulletin, 24(6), 563-574

Lerner, J. S., Gonzalez, R. M., Small, D. A., \& Fischhoff, B. (2003). Effects of fear and anger on perceived risks of terrorism: A national field experiment. Psychological Science, 14(2), 144-150.

Little, A. T. (2016). Communication technology and protest. The Journal of Politics, 78(1), 152-166.

Makgetlaneng, S. (2005). Zimbabwe's 2005 parliamentary elections: Lessons for the Movement for Democratic Change. Journal of African Elections, 4(2), 123-141.

Manacorda, M., \& Tesei, A. (2020). Liberation technology: Mobile phones and political mobilization in Africa. Econometrica, 88(2), 533-567.

McCandless, E. (2011). Polarization and Transformation in Zimbabwe: Social movements, strategy dilemmas and change. Lexington Books.

Miller, J. M., \& Krosnick, J. A. (2004). Threat as a motivator of political activism: A field experiment. Political Psychology, 25(4), 507-523.

Pan, J., \& Siegel, A. (2020). How Saudi crackdowns fail to silence online dissent. American Political Science Review, 114(1), 109-125.

Pearlman, W. (2013). Emotions and the microfoundations of the Arab uprisings. Perspectives on Politics, 11(2), 387-409.

Ridout, T. N., \& Searles, K. (2011). It's my campaign I'll cry if I want to: How and when campaigns use emotional appeals. Political Psychology, 32(3), 439-458.

Roberts, M. E. (2018). Censored: Distraction and diversion inside China's Great Firewall. Princeton University Press.

Roseman, I. J., Wiest, C., \& Swartz, T. S. (1994). Phenomenology, behaviors, and goals differentiate discrete emotions. Journal of Personality and Social Psychology, 67(2), 206-221.

Ryan, T. J. (2012). What makes us click? Demonstrating incentives for angry discourse with digitalage field experiments. Journal of Politics, 74(4), 1138-1152.

Sachikonye, L. (2011). When a state turns on its citizens: 60 years of institutionalized violence in Zimbabwe. Weaver Press.

Scott, J. C. (1990). Domination and the arts of resistance: Hidden transcripts. Yale University Press.

Smith, C. A., \& Ellsworth, P. C. (1985). Patterns of cognitive appraisal in emotion. Journal of Personality and Social Psychology, 48(4), 813-838.

Southall, R. (2013). How and why ZANU-PF won the 2013 Zimbabwe elections. Strategic Review for Southern Africa, 35(2), 135-151. 
Steinert-Threlkeld, Z. C., Mocanu, D., Vespignani, A., \& Fowler, J. (2015). Online social networks and offline protest. EPJ Data Science, 4(1), 1-9.

Tannenbaum, M. B., Hepler, J., Zimmerman, R. S., Saul, L., Jacobs, S., Wilson, K., \& Albarracín, D. (2015). Appealing to fear: A meta-analysis of fear appeal effectiveness and theories. Psychological Bulletin, 141(6), 1178-1204.

Tufekci, Z., \& Wilson, C. (2012). Social media and the decision to participate in political protest: Observations from Tahrir square. Journal of Communication, 62(2), 363-379.

Valentino, N. A., Hutchings, V. L., \& White, I. K. (2002). Cues that matter: How political ads prime racial attitudes during campaigns. American Political Science Review, 96(1), 75-90.

Weber, C. (2013). Emotions, campaigns, and political participation. Political Research Quarterly, $66(2), 414-428$.

Young, L. E. (2019). The psychology of state repression: Fear and dissent decisions in Zimbabwe. American Political Science Review, 113(1), 140-155.

Zamchiya, P. (2013). The MDC-T's (Un) seeing eye in Zimbabwe's 2013 harmonised elections: A technical knockout. Journal of Southern African Studies, 39(4), 955-962.

Zeitzoff, T. (2017). How social media is changing conflict. Journal of Conflict Resolution, 61(9), 1970-1991.

Publisher's Note Springer Nature remains neutral with regard to jurisdictional claims in published maps and institutional affiliations.

\section{Authors and Affiliations}

\section{Lauren E. Young ${ }^{1}$}

Lauren E. Young

leyou@ucdavis.edu

http://www.laurenelyssayoung.com

1 UC Davis, Davis, USA 